\title{
La base de valores ético-empresariales en el ámbito multicultural ${ }^{1}$
}

\author{
Iosif M. DZYALOSHINSKY \\ idzyaloshinsky@hse.ru \\ National Research University Higher School of Economics (Moscú, Rusia) \\ Maria A. PILGuN \\ pilgunm@yandex.ru \\ National Research University Higher School of Economics (Moscú, Rusia) \\ Olga KorenevA \\ okoreneva@ugr.es \\ Universidad de Granada
}

Recibido: 2 de abril de 2014

Aceptado: 9 de septiembre de 2014

\section{Resumen}

A causa de la creciente importancia de las normas éticas en la comunicación y las actividades el presente estudio identifica la base de valores subyacentes a la conducta empresarial en el entorno de la comunicación de negocios y sus estructuras globales. El estudio pretendió obtener datos empíricos acerca de los valores que condicionan el comportamiento de los empresarios de los países Alemania, Francia, EEUU, España, Rusia, etc. cuya interacción determina la situación en el mercado europeo y mundial. Se comprobó la hipótesis de que, junto al reducido número de valores culturales comunes, las bases de valores éticos de negocios difieren impidiendo la comunicación y la actividad empresarial multicultural efectiva y ponen en duda la transición masiva del Occidente al post-materialismo, al menos para el importante grupo social, como lo es el empresario.

Palabras clave: ámbito multicultural, valores culturales, comunicación, ética comercial, regulación ética.

\section{The Valuable Bases of Business Ethics in Multicultural Environment}

\begin{abstract}
Because of the increasing importance of ethical standards in business communication and activities the present research approach differs from methods traditionally applied in other studies in the same area, as it addresses profound ethical values underlying business conduct within the global interaction of business structures. The main study objective was gathering information on the true values which determine the entrepreneur's behavior of the countries (Germany, France, USA, Spain, Russia, etc.) whose activities influence the general situation on the European and world market. The following hypothesis was to prove: European culture countries undoubtedly share a certain common values, but their market players show very different business ethics grounds, that is a serious obstacle for effective intercultural communication and makes doubtful the general Western shift to the post-materialism - at least regarding the business community.

Keywords: Multicultural environment, cultural values, communication, business ethics, ethical regulation.

\section{Referencia normalizada}

DZYALOSHINSKY, Iosif M.; PILGUN, Maria A.; y KORENEVA, Olga (2015): "La base de valores ético-empresariales en el ámbito multicultural”. Estudios sobre el Mensaje Periodístico. Vol. 21, Núm. 1 (enero-junio), págs.: 299-315. Madrid, Servicio de Publicaciones de la Universidad Complutense.
\end{abstract}

1 Con la financiación de Russian Scientific Humanitarian Fund. With the support of Russian Scientific Humanitarian Fund. 
Sumario: 1. Introducción. 2. ¿Qué sucede con los valores?. 3. Método; 3.1. Los participantes; 3.2. Herramientas de la investigación; 3.3. Procedimientos; 3.4. La fórmula. 4. Resultados y discusión. 5. Conclusiones. 6. Referencias bibliográficas. 7. Anexos.

\section{Introducción}

La relevancia del presente estudio de valores culturales básicos en el ámbito multicultural debe al hecho de que durante la crisis económica mundial surgen tensiones y los problemas de la comunicación intercultural en el ámbito de negocios se acentúan. La eficacia en la interacción de los representantes de distintas culturas se ve disminuida por la influencia negativa de la crisis económica y política que impide el entendimiento y el alcance de acuerdos beneficiosos mutuos a la hora de solucionar problemas surgidos.

Por razones de la globalización resulta lógico que hoy día el análisis de distintos aspectos de la comunicación intercultural llama especial atención. Para optimizar los procesos de la comunicación internacional es necesario estudiar las nociones típicas ancladas en la forma de percepción al nivel nacional, identificar los paradigmas lingüístico-mentales prototípicos para cada cultura, determinar la correlación de las imágenes mentales y estrategias de comportamiento, al igual que establecer las características integrales y diferenciales correspondientes a los modelos estratégicos y situacionales del comportamiento de los portadores de distintas culturas.

No por casualidad en los últimos veinte años las cuestiones culturales de la ética empresarial atraen cada vez más la atención de los investigadores, gestores y líderes políticos. Los cursos de comunicación multicultural y de ética se han vueltos asignaturas obligatorias en todas las escuelas de negocios. Los resultados de investigaciones muestran que los empresarios consideran la ética de las relaciones externas e internas una de las condiciones más importantes de la comunicación internacional exitosa y que ésta representa uno de los componentes más relevantes en la evaluación global de la imagen de una empresa.

El objetivo principal del presente estudio ha sido la obtención de los datos empíricos sobre los valores interculturales que determinan el comportamiento de los empresarios de los países más importantes (Alemania, Francia, España, Rusia, EE.UU. etc.) cuya interacción influye en el estado de los principales mercados europeos y mundiales. Igualmente, se pretende identificar los valores que forman la imagen del negocio y de los empresarios pertenecientes a culturas diferentes con el objetivo de describir la ética de negocios.

El término "cultura" hace referencia al conjunto de conocimientos, valores, normas, garantizando la adaptación humana a la comunidad o la transformación de ésta de acuerdo con sus necesidades, objetivos e ideas. La cultura existente en un momento determinado refleja la realidad en la que previamente vivieron los grupos étnicos y grupos sociales y a la que se han adaptado con eficacia (Dzyaloshinsky, 2013).

En cuanto a la ética, se refiere al conjunto de normas, actitudes y normas que guían a las personas en su comportamiento real en las diferentes esferas de la vida, incluido el empleo. Ya la fuente lexicográfica rusa más antigua el "Diccionario de la Academia Rusa" (1783) describe la moralidad. La moral aparece como un regulador de las relaciones sociales desde dentro. Desde el punto de vista psicológico, la regulación 
moral es una evaluación y prescripción y presupone la aprobación o desaprobación de las acciones de personas. Las normas generales de la moral se expresan en las representaciones fijas (mandamientos, principios, códigos) sobre cómo hacer y qué no hacer. Cuando se habla de la moralidad se hace referencia al juicio sobre lo correcto e incorrecto, el bien y el mal, la justicia y la injusticia. Es evidente que la moral pertenece al mundo de la cultura y a la naturaleza humana (flexible y creada por ellos mismos) y forma parte de la relación pública (artificial) entre los individuos (Dzyaloshinsky y Pilgún, 2013).

Como el objeto del estudio se han seleccionado los valores culturales que se consideran fundamentales para el comportamiento humano. Existen numerosos trabajos donde se ofrecen tipologías de valores distintas: por ejemplo, para identificar los valores de una organización a menudo se utiliza la comúnmente conocida metodología de Schwartz (1993), dentro de la cual se encuentran 10 valores:

- Potencia: la condición social, el dominio sobre las personas y los recursos

- Logro: el éxito personal en línea con las normas sociales

- Hedonismo: el placer o el gozo sensual

- Estimulación: la emoción y la novedad

- Auto-dirección: la capacidad de pensar y actuar por sí mismo

- Universalismo: la comprensión, la tolerancia y defensa del bienestar de todas las personas y la naturaleza

- Benevolencia: mantener y mejorar el bienestar de sus seres queridos

- Tradición: el respeto y la responsabilidad de las costumbres y las ideas culturales y religiosas

- Conformidad: la contención de acciones e incentivos que podrían perjudicar a otros y no cumplen con las expectativas del grupo social

- Seguridad: la seguridad y estabilidad de la sociedad, de las relaciones y de sí mismo.

Un enfoque interesante en las cuestiones de los valores está indicado en la teoría de la personalidad de Maslow (1954). Según su teoría, la fuerza impulsora es el deseo humano para la mejor identificación y desarrollo de sus posibilidades personales. Este deseo se sitúa en el nivel más alto en la jerarquía de las necesidades humanas. Todas las personas auto-realizadas tienden a realizar sus valores cotidianos que son sus necesidades vitales. Maslow distingue los valores cotidianos (valores más altos inherentes de las personas que buscan la auto-realización) - la verdad, la bondad, la belleza, etc. - y valores deficientes - valores del orden más bajo.

El concepto de la personalidad de Frankl (1982), tal y como está reflejado en la teoría de la logoterapia y análisis existencial, tiene como el componente central "la razón de vivir". Frankl (1982: 123) considera "que la razón de vivir no es importante en sí, sino más bien el sentido de vida específico de una persona concreta en el momento dado".

Leontiev (1992) propone considerar la estructura jerárquica individual de la orientación de valores en forma de ciertos "bloques" que vinculan los valores por diversas razones: 
A) Valores terminales:

1. Los valores concretos de la vida (salud, trabajo, amigos, vida familiar), valores abstractos (la cognición, el desarrollo, la libertad, la creatividad)

2. Los valores de la auto-realización profesional (trabajo interesante y vida productiva, creatividad, vida laboral activa); el valor de su vida personal (salud, amor, amigos, diversión, vida familiar)

3. Los valores personales (salud, creatividad, libertad, vida laboral activa, diversión, confianza en sí mismo, buen nivel adquisitivo); valores relacionados con el ámbito interpersonal (amigos, vida familiar feliz, felicidad de los demás)

4. Valores activos (libertad, vida laboral activa, actividades productivas, trabajo interesante); valores pasivos (naturaleza y arte, seguridad en sí mismo, conocimiento, sabiduría vital)

B) Los valores instrumentales:

1. Valores éticos (honestidad, intolerancia hacia los defectos); valores relativos al ámbito interpersonal (educación, alegría vital, sensibilidad); valores de la autorrealización profesional (responsabilidad, fuerza de voluntad, diligencia)

2. Valores individualistas (altas ambiciones, independencia, fuerza de voluntad); valores conformistas (diligencia, autocontrol, responsabilidad); valores altruistas (tolerancia, sensibilidad, mente abierta)

3. Valores de auto-afirmación (ambiciones altas, independencia, intransigencia, coraje, fuerza de voluntad); valor de la aceptación de los demás (tolerancia, sensibilidad, mente abierta).

4. Valores intelectuales (formación profesional, racionalismo, auto-control)

5. Valores relacionados con la percepción directa del mundo (alegría vital, honestidad, sensibilidad) (Leontiev, 1992).

Rokeach (1973), por ejemplo, distingue también valores terminales e instrumentales. Los primeros están relacionados con la convicción de que el objetivo final personal o social de toda la existencia de un individuo tiene que merecer la pena. Los valores instrumentales están relacionados con la convicción de que una acción determinada desde el punto de vista personal o social es preferible en todas las situaciones. Los valores terminales son más estables que los instrumentales y se caracterizan por una menor variabilidad interindividual.

\section{2. ¿Qué sucede con los valores?}

Se observa la existencia de dos paradigmas básicos relacionados con la dinámica de los cambios en los sistemas de valores: positivo y negativo. Un ejemplo de un paradigma positivo está descrito en las publicaciones de Inglehart (1996) del Instituto de Investigaciones Sociales de la Universidad de Michigan (EE.UU.). El investigador parte del material contenido en la base de datos única "Encuesta Mundial de Valores". Ésta incluye datos procedentes de 43 sociedades representadas por el $70 \%$ de la población mundial, cuyos ingresos anuales per cápita oscilan entre de sólo $300 \$$ y unas cien veces más, empezando por las democracias de economías de mercado esta- 
blecidas hace mucho tiempo y acabando en los países con sistemas autoritarios o antiguos estados de régimen socialista. El análisis de esos datos permite llegar a la conclusión de que para la mayor parte de la población de la sociedad industrial avanzada la libertad de expresión y la creciente participación en la vida política van ganando cada vez más importancia. Después de la Segunda Guerra Mundial en la mayoría de los países industrializados en consecuencia de un rápido crecimiento económico se produce un desarrollo acelerado de estructuras estatales. También gracias al aumento del bienestar de los grupos sociales de generaciones posteriores, se puede presuponer que surgen otras prioridades de valores en comparación con las generaciones anteriores. Según Iglehart (ibid), el cambio hacia los valores del post-modernismo no sucede por primera vez en la historia de los cambios culturales importantes. Por ejemplo, lo mismo sucedió durante la transición de una sociedad agraria hacia una sociedad industrial, lo que significó el desprendimiento de la percepción del mundo dictado por la economía rígida.

El paradigma negativo está presentado en el libro de Selchonok (2000) "La seguridad axiológica y métodos de su aseguramiento". El autor de este trabajo afirma que hemos sido testigos (y aún lo seguimos siendo) de un drama histórico que se caracteriza por una catástrofe axiológica global, que sólo se puede comparar con el cataclismo natural del planeta. Califica todos los acontecimientos en la antigua Unión Soviética como "resultado de la negligencia criminal de los líderes soviéticos hacia la seguridad axiológica que llevó, como era de esperar, a la caída de los valores globales de los representantes de varias generaciones". En su opinión, "la destrucción de los sistemas de valores originó la atomización social de la gran mayoría de los ciudadanos de la antigua Unión Soviética cuyas necesidades se situaron en el eje horizontal. Es obvio que el mundo moderno se ha visto ante la destrucción casi completa del sistema de transmisión de los valores tradicionales. El desvanecimiento de las instituciones tradicionales, tales como la familia, la comunidad religiosa, la cultural y la de la educación pública tuvo que tener su impacto en el bienestar del pueblo. El crecimiento de la actividad criminal, la profundización del escapismo de la juventud, la propagación del suicidio y el abuso de las sustancias adictivas entre los adolescentes apuntan claramente a la necesidad de la pronta aplicación de un sistema adecuado de educación basada en valores" (Selchonok, 2000:2).

La hipótesis del presente estudio consiste en la suposición de que tanto el paradigma positivo, como el negativo no reflejan toda la complejidad de las transformaciones axiológicas, ya que junto a los valores coincidentes y característicos para los países con la cultura europea o los que están bajo su influencia, la base ética de diferentes países se distinguen fundamentalmente. Este hecho impide la comunicación económico-cultural eficaz.

La motivación de los autores del presente estudio para formular dicha hipótesis y para comprobar su certeza ha sido la manifestación del hecho de que los esfuerzos descomunales de muchos países para la mejora de la ética empresarial no traen suficientes frutos. Las Naciones Unidas, la Cámara de Comercio Internacional y la Organización para la Cooperación y el Desarrollo Económico (OCDE) adoptaron en su momento los códigos internacionales de conducta empresarial. La imagen ejemplar del sistema mun- 
dial de normas éticas se puede ver también en los "Principios de negocios" establecidos en 1994 durante la Mesa Redonda en la ciudad suiza de Caux por líderes empresariales de Japón, Europa Occidental y Estados Unidos que hasta la fecha han ganado plena aceptación en la comunidad empresarial internacional. Su objetivo era desarrollar un código de conducta común para los empresarios pertenecientes a dos sistemas de conducta empresarial fundamentalmente distintos: occidental y oriental (Asia).

Una influencia importante a la formación de la ética empresarial tenían el Pacto Mundial de la ONU, acuerdo de Keidanren sobre la buena conducta corporativa, la iniciativa global de la Guía para la elaboración de informes (GRI), así como la norma SA8000 que en la actualidad está adquiriendo cada vez más y más popularidad y hace referencia al sistema de la gestión social y ética. SA8000 estándar fue desarrollado en 1999 bajo los auspicios de la organización de la defensa de derechos humanos Responsabilidad Social Internacional (Social Accountability International-SAI). Sus requerimientos parten de las convenciones de la Organización Internacional del Trabajo (OIT) y de las de otras organizaciones para la defensa de los derechos humanos. Su sistema de verificación independiente se basa en los procedimientos utilizados en la certificación de la norma ISO 9000 y 14000 . Así, esta norma en particular, integra la prohibición establecida para las empresas de no emplear a niños menores de quince años, no obligar a los trabajadores a trabajar contra su voluntad, prescribe tomar las medidas necesarias para garantizar la salud y seguridad de los empleados. Algunas de las normas recomiendan a las empresas públicas desarrollar y aplicar códigos de conducta y sistemas de la ética corporativa como una manera de presentar los principios del funcionamiento de la organización a los grupos de interés internos y externos a la empresa.

Hoy en día hay cerca de 200 convenios y recomendaciones internacionales, como las normas laborales internacionales destinadas a humanizar y democratizar el mundo laboral que buscan la defensa social y la creación de condiciones favorables. En Europa, las correspondientes normas democráticas básicas están fijadas en la forma de la Carta comunitaria de los derechos sociales fundamentales de los Trabajadores (Carta Social Europea del Consejo de Europea).

En cuanto a Rusia, los primeros brotes en el campo de la ética empresarial rusa moderna comenzaron a salir en los años 90. Entonces fue adoptada una serie de códigos de ética profesional, entre los cuales se pueden mencionar:

- Código de Honor de banqueros (1992)

- Condiciones de los miembros de Comercio Justo de la Asociación Profesional de Agentes del Mercado de Valores (1994)

- El código de honor de los miembros de la Asociación Rusa de agentes inmobiliarios (1994)

- Código de ética de los miembros de la Sociedad Rusa de tasadores (1994).

Sin embargo, a pesar de todos los esfuerzos, desgraciadamente muy a menudo la ética empresarial se reduce al protocolo, que consiste en un sistema de normas de cortesía, incluyendo formas de presentarse, saludos y despedidas, expresiones de gratitud y simpatía, arte de hablar en público, la capacidad de mantener una conversación, el correcto comportamiento durante las comidas, expresar felicitaciones, hacer rega- 
los, etc. En cuanto al comportamiento real de las estructuras de negocios en los mercados nacionales e internacionales, una conseguida descripción ofrece Naomi Klein $(2003,2005,2009)$ en sus libros.

Los autores del presente estudio están convencidos de que cualquier sistema ético es una construcción dinámica, basada en los valores fundamentales reconocidos por la comunidad como la guía principal de comportamiento personal y profesional. La esencia del valor es una imagen fijada que refleja la importancia de los fenómenos humanos y culturales que constituyen su mundo. La cultura humana está impregnada de las relaciones entre sus valores. Pero, aunque esté tejida de ellas, no es un producto de la conciencia y herencia humanos subjetivos. La cultura humana es un mundo objetivo, jerárquicamente organizado que, a la vez, es interiormente contradictorio en sí mismo en cada eslabón de su jerarquía. Este mundo se le concede a cada hombre un hábitat natural que necesita ser dominado. Y este proceso no puede y no debe ser puramente teórico y no representa un conocimiento racional, sino que se trata precisamente de un dominio, o sea, un proceso de interiorización para ir formando parte de su identidad propia. La medida del dominio cultural humano del mundo es una medida de la humanidad del hombre, al menos una de las medidas, ya que hay otras, tales como: la contribución del hombre al mundo de los valores humanos.

El presente artículo describe el proyecto de investigación y sus resultados con la intención de identificar empíricamente los elementos del sistema de valores básicos que forman parte del fundamento ético, en este caso del ámbito empresarial, que reina en diferentes países.

\section{Método}

\subsection{Los participantes}

Durante el presente estudio se entrevistaron a 500 participantes de diferentes países: España, Rusia, Gran Bretaña, EE.UU., Italia, Alemania y Francia. La participación de hombres y mujeres era de aproximadamente $50 \%$ y se abarcó todas las edades empezando por alumnos de institutos y acabando por los jubilados mayores de 55 años. De esta forma estaban presentes todos los grupos sociales (ver estadística del estudio en el anexo, Tabla 1).

\subsection{Herramientas de la investigación}

Para la captura de datos la encuesta se realizó en la plataforma Unipark que permite crear encuestas en diferentes lenguas, formando así una sola matriz de datos para todas las lenguas. Actualmente Unipark forma parte de la empresa QuestBack (anteriormente Globalpark). La metodología QuestBack Internet se basa en el principio de la EFS-vista (MySQL, PHP, Apache y Linux) y se correlaciona con la información del centro de QuestBack. Su módulo multilingüe permite realizar una encuesta en ruso, inglés, francés, alemán, español e italiano.

Después de realizar todas las encuestas, los resultados fueron exportados al programa Excel para su análisis. Los datos tenían forma de matriz, donde cada fila visualizaba todas las respuestas de un entrevistado y estaba representada por un número que se corresponde con las opciones de respuesta seleccionadas. Por lo tanto, era po- 
sible calcular los valores medios basados en uno o varios parámetros, tales como, por ejemplo: la edad, el nivel educativo, ocupación de los participantes.

\subsection{Procedimientos}

Se pidió a los encuestados que completaran un cuestionario en el que se encontraron enumerados al azar a los diferentes valores o cualidades que en mayor o menor medida afectan al comportamiento empresarial. Las listas de estos valores fueron formuladas a partir de encuestas a expertos en la materia y traducidas a las lenguas de los participantes. Se obtuvieron los siguientes valores: seguridad, religiosidad, poder, deber, abundancia, salud, amor, independencia, formación, igualdad, libertad, familia, justicia, amor por la patria, tolerancia, creatividad, trabajo, placer, éxito, democracia, progreso, riqueza, conformismo, eficiencia, prosperidad, utilidad, ciencia, poder judicial, confort, libertad personal, sinceridad. Basándose en su propia experiencia o información obtenida de diversas fuentes (cine, literatura, televisión, etc.) los participantes debían estimar según la escala de 1-5 el grado de prototipicidad de cada valor para empresarios de diferentes países ( 1 - el valor que les caracteriza a nivel mínimo, 5 - al máximo).

\subsection{La fórmula}

Para resumir los datos se utilizó una fórmula que tiene en cuenta el valor medio en el intervalo especificado considerando al mismo tiempo varias condiciones con sus datos correspondientes.

Una de las condiciones era el valor mayor que 0 para eliminar el error en los cálculos debido a las respuestas dejadas en blanco que fueron codificados como 0 . Los valores significativos de la calidad o valor variaron de 1 a 5 .

Como otras condiciones figuraban los parámetros de los participantes en el estudio. Se ha podido calcular el promedio de las estimaciones sobre tales parámetros, como: nacionalidad, edad, educación, ocupación, etc. Las calificaciones del promedio calculadas para todas las estimaciones indicadas por los participantes se convierten en las puntuaciones medias, calculadas por todas las cuentas, según los cuestionarios de todos los participantes en la encuesta en cada país. También se ha podido establecer el grado de importancia de los diferentes valores para las diferentes culturas empresariales, según los encuestados (puntuaciones medias, calculadas por todas las estimaciones, incluidas en los cuestionarios de todos los participantes en la encuesta en cada país).

Los datos obtenidos tras el tratamiento estadístico se clasificaron en orden descendente lo que permitió determinar y comparar la jerarquía de valores (media de todos los encuestados o por diferentes países).

\section{Resultados y Discusión}

Los datos obtenidos proporcionan la base para formular una serie de conclusiones.

1. Se observa el extremadamente alto grado de diferenciación de base de valores ético-empresariales en los países del estudio. Por ejemplo, entre los empresarios del sur de Europa (España, Italia) y sus colegas nórdicos existen diferencias significati- 
vas en los valores fundamentales que definen su comportamiento. Mientras que para los españoles y los italianos los valores más importantes de la vida son "la diversión" y "la familia" (ver Anexo, Tabla 2: "placer", "familia" y Tabla 3), para sus homólogos, por ejemplo, alemanes lo son el "éxito" y "la seguridad" (ver Anexo, Tabla 2, "trabajo", "eficiencia" y Tabla 3). Si comparamos los empresarios angloparlantes, sus valores fundamentales también son diferentes: "el poder" y "el amor por la patria" para los estadounidenses y "la seguridad" y "el éxito" para los británicos. En lo que concierna a los empresarios franceses, en primera línea aparecen tales valores, como "el amor por la patria" y "la formación", mientras que para los rusos lo son "el poder" y "el amor por la patria" (ver Anexo, Tabla 2 y 3 ).

2. Resultó ser llamativa la coincidencia en los valores de las más altas calificaciones, que es "el poder" para los hombres de negocios rusos y estadounidenses (ver Anexo, Tabla 2 y 3). Las afirmaciones sobre la diferencia fundamental entre la cultura ética del Occidente basada en los cánones del protestantismo y la cultura ética de Rusia que haya absorbido, según algunos investigadores, los valores fundamentales de la religión ortodoxa, no encuentran sus pruebas en los resultados en el presente estudio. Por lo cual, las diferencias entre estas dos corrientes religiosas parecen requerir una revisión a fondo.

3. Del estudio resultó que "la libertad", "la independencia" y "la libertad personal" no fueron posicionados en las cabeceras de los rankings para ninguno de los grupos seleccionados (ver Anexo, Tabla 3). Esto sugiere que el concepto de Inglehart sobre el cambio generalizado en el mundo occidental hacia los valores post-materialistas todavía necesita ser probado, por lo menos en un grupo social tan importante, como lo son los empresarios.

4. Se considera comúnmente que la revolución ética que se está observando actualmente en el ámbito empresarial está relacionada con la extensión global del concepto de responsabilidad social. En consecuencia, el objetivo de la empresa no es sólo la obtención del beneficio y la satisfacción de las necesidades de los clientes, sino está marcado por la abiertamente manifestada preocupación por el bienestar de la sociedad en su conjunto a largo plazo. Sin embargo, este proceso revolucionario no tuvo ningún efecto a la percepción personal profunda de los encuestados.

5. Otra conclusión deducible e importante confirma una vez más que los perfiles de valores por los que se guían los empresarios no son una combinación caótica de entidades diferentes, sino representan una construcción que refleja la estrategia de vida de las personas encuestadas. Y desde este punto de vista, se visualiza claramente tres estrategias ideales, que se remontan a los arquetipos de personas anclados en las culturas mundiales: "sacerdote", "guerrero" y "labrador". En el transcurso de su desarrollo histórico éstos se han ido transformando en unos patrones de personalidad comunes: monje (un Santo), caballero (héroe) y el maestro (definido como una persona dedicada al trabajo productivo).

El patrón personal de un Santo (o un asceta) guía a una persona por el camino hacia las limitaciones o la represión de los deseos sensuales para lograr la libertad de la necesidad. Desde los siglos pasados hasta el presente sigue habiendo la imagen de un as- 
ceta, desinteresado, el filósofo, quien no consiguió ni el puesto importante, ni el dinero, no saboreó las alegrías de la vida, no es comprendido ni por la familia, ni por los amigos. Hay que subrayar que en los resultados del estudio no se han encontrado indicios del ideal ascético.

La otra imagen muy arraigada en el paradigma cultural de todos los países europeos y asiáticos corresponde a la imagen de un caballero, guerrero, héroe conquistador y vencedor. Basta con recordar los héroes paganos (personificados en la mitología griega, germana y otras) que se centraban en la conquista, la victoria, la destrucción, robo, los objetivos vitales de los cuales destacan el orgullo, el poder, la gloria y la superioridad sobre los demás. Una característica típica de este modo de vida es el rechazo absoluto de la vida cotidiana, el desprecio por el trabajo (especialmente físico) como forma de ganarse la vida, el deseo de auto-realización en actos heroicos y la ambición desmesurada. El fundamento del patrón de un caballero es la creencia de que el honor y la dignidad están por encima de toda la riqueza y de la vida misma.

En Europa la personalidad del caballero heroico, una vez enterrado por Cervantes, fue nuevamente llamada a la vida en las obras de Nietzsche y de otros estudiosos culturales que han reflejado en sus trabajos los ideales heroicos de la caballería. Fromm (1986) hizo algunos comentarios interesantes sobre la materia:

"Si nos fijamos en nosotros mismos, en el comportamiento de casi todos los pueblos y de nuestros líderes políticos, no podemos negar que nuestras ideas de la bondad y nuestros valores son los mismos que los del héroe pagano. Toda la historia europeo-americana, a pesar de la cristianización, es la historia de la conquista, sometimiento y la codicia; los valores más reconocidos de nuestra vida son ser más fuerte que otros, ganar las batallas, conquistar a los otros y explotarlos. Estos valores coinciden con el ideal de la "masculinidad": solo el que es capaz de luchar y de ganar es un hombre de verdad, el que no utiliza la fuerza para lograr sus objetivos es débil y no es un hombre". Fromm (1986:165)

Por lo tanto, concluye Fromm, la cristianización de Europa fue en gran medida un engaño, en el mejor caso sólo se puede hablar de la cristianización parcial en los siglos XII y XVI. Sin embargo, este corto período de cristianización terminó y Europa regresó a sus origines paganos.

Precisamente este ideal también se vislumbra en las jerarquías de valores obtenidas durante este estudio.

El tercer modo de la vida es el maestro, es decir, la persona que fue capaz de demostrar el más alto grado de su capacidad creativa, la persona que crea cosas cualitativamente nuevas y únicas (el mayor grado del maestro - es el genio), que abre a la humanidad los caminos nuevos y desconocidos. En cuanto a la personalidad del maestro, ésta está orientada hacia la actividad creativa muy sacrificada que conduce a la creación de entidades principalmente nuevas, al descubrimiento de creaciones únicas que abren nuevas vías para la actividad humana. Cabe recordar que la orientación de la actividad creativa hacia la utilidad para la comunidad siempre ha sido considerada como una característica importante de la parte de la población que la humanidad denomina como genios.

En la cultura occidental, después de que Cervantes definitivamente destruyó con su Don Quijote la ideología caballeresca, prevaleció el arquetipo del maestro. No en 
vano, está muy extendida la tesis de la filosofía católica de la vida que es: "ora et labora" (ora y trabaja). Los descendientes de los maestros medievales crearon un sistema específico de valores, que es retratado vívidamente en la "Autobiografia" de Benjamin Franklin (1956) donde éste enumera las virtudes que pretendía inculcarse a sí mismo: 1) la moderación en la comida y bebida; 2 ) la reticencia (evitar el hablar por hablar, ya que eso es inútil para los interlocutores); 3) el orden; 4) la determinación, el cumplimiento de los acuerdos; 5) el ser ahorrativo; 6) la diligencia; 7) la sinceridad (no admitir engaños); 8) la justicia; 9) la moderación; 10) la limpieza, la pulcritud en la vestimenta y la vivienda; 11) la serenidad, que hace referencia a la capacidad de no alterarse por cosas sin importancia o por causa de percances comunes o inevitables; 12) la castidad y 13) la modestia (Franklin, 1956: 482-483).

Cabe subrayar que en el transcurso del estudio no fue detectada ninguna de las virtudes enumeradas por Franklin. Pero se identificaron elementos distintos al estilo de vida conocido en los siglos pasados. Se trata de estilo de vida que puede ser llamado glamuroso y hedonista. Este en la antigüedad ligeramente despreciable estilo anteriormente tenía carácter adicional a otros estilos esenciales. Pero en los últimos años se ha convertido para muchos en básico. Debido a su incompatibilidad con las metas del espacio vital desarrollado por la nueva ética europea, el estilo glamuroso pone de manifiesto la aparición de nuevas dimensiones de la cultura europea en general.

Cabe añadir que el análisis de los datos obtenidos durante el estudio permitió sacar las conclusiones de que el perfil de valores del empresario español, tal y como lo ven los mismos españoles encuestados (ver Anexo, Tabla 4), coincide prácticamente en todo con la opinión de la totalidad de los encuestados (ver Anexo, Tabla 2). Este hecho pone de manifiesto la alta integración del empresariado español en la actividad y la comunicación europea y mundial lo que permite esta coincidencia entre la autoevaluación y la opinión de los demás. Al mismo tiempo se pude observar que las características de los representantes de los negocios de otros países consideradas por los españoles encuestados como típicas se aproximan mucho al perfil determinado según los datos obtenidos en la encuesta masiva (ver Anexo, Tablas 3 y 5).

\section{Conclusiones}

De esta forma, los resultados del presente estudio confirman la certeza de la hipótesis formulada. Se ha podido comprobar que junto a un número reducido de valores coincidentes en países con cultura europea o los que sufren su influencia, la base éticoempresarial de los representantes de países diferentes se distingue fundamentalmente, lo que impide alcanzar la comunicación intercultural eficaz.

Por lo tanto, el estudio ha demostrado que los cambios globales que tienen lugar en el mundo contemporáneo generan una nueva combinación de modelos éticos capaces de provocar situaciones y consecuencias imprevisibles. Se puede afirmar que la ética moderna se ha enfrentado con los problemas cuya solución determinará el destino del desarrollo social y cultural. Mucho dependerá de la voluntad de los empresarios procedentes de diferentes países para conocer las características de los sistemas éticos que regulan las normas de comportamiento de sus socios, competidores y consumidores que viven en otros sistemas socio-culturales. 
Al mismo tiempo, se hace evidente que la globalización conlleva la creación de una especie de campo axiológico común que obliga al cumplimiento de las normas morales establecidas. Con otras palabras, se trata de que los diversos códigos y doctrinas éticas no deben basarse en las buenas intenciones de sus creadores, sino partir del análisis de los valores básicos reales de cada cultura determinada.

De esta forma, el estudio realizado ha aportado un valioso material para el futuro análisis más profundo de los valores culturales subyacentes que condicionan el comportamiento de los empresarios de diferentes países y determinan la imagen del negocio y de sus representantes. Dicho análisis es necesario para mejorar la comunicación a nivel global y alcanzar un mejor entendimiento a todos los niveles.

\section{Referencias bibliográficas}

MASLOW Abraham H. (1954): Motivation and Personality. New York, Harper.

ROKEACH, Milton (1973): The Nature of Human Values. New York, The Free Press.

SCHWARTZ, Shalon H. (1993): "Comparing value priorities across nations", Invited address at 24 Congress of the Interamerican Society of Psychology. Santiago, Chile, July.

ДЗЯЛОШИНСКИЙ, И.М. [Dzyaloshinsky, I.M.] (2013): Коммуникаиионные проиессы в обществе: институты и субъекты [Procesos comunicativos en la sociedad: instituciones y sujetos]. Дзялошинский, И.М. (ed) Монография Moscow: Издательство АПК и ППРО.

ДЗЯЛОШИНСКИЙ, И.М., Пильгун М.А. [Dzyaloshinsky, I.M. and Pilgun, M.A.] (2013): Ценностные основания бизнес-этики: результаты международного исследования. [Las bases éticos del negocio] Монография. Моscow: АПК и ППРО.

ИНГЛХАРТ, Р. [Inglehart, R.] (1996): “Постмодерн: Меняющиеся ценности и изменяющиеся общества" ["Postmodernismo: los valores y la sociedad cambiantes"], en Sociology Mehphi: http://www.sociology.mephi.ru/docs/polit/html /ingl.htm [fecha de consulta: 02.03.2012]

КЛЯЙН Н. [Klein, N.] (2003): NO LOGO: Люди против брендов. [No logo: la humanidad contra las marcas], Moscow: Добрая книга.

КЛЯЙН Н. [Klein, N.] (2005): Заборы и окна [Muros y ventanas], М.: Добрая книга.

КЛЯЙН Н. [Klein, N.] (2009): Доктрина шока. Расивет капитализма катаcmpoф [Doctrina de choque. El capitalismo catastrófico en flor]. Moscow: Добрая книга.

ЛЕОНТЬЕВ, Д.А. [Leontjev, D.A.] (1992): Методика изучения иенностных ориентаиий [La metodología del estudio de las orientaciones de valores], Moscow.

СЕЛЬЧЁНОК, К.В., [Selchonok, K.W.] (2000): Аксиологическая безопасность и методы ее обеспечения [La seguridad axiológica y los métodos para garantizarla]. Минск. 
ФРАНКЛ В. [Frankl, V.] (1982): “Поиск смысла жизни и логотерапия” [Búsqueda de la razón de vivir y la logoterapia], en Психология личности [Psicología de la personalidad]. Тексты. - Moscow: МГУ.

ФРАНКЛИН Б. [Franklin, В.] (1956): “Автобиография” [“Autobiografia”]. Избр. произв. [Obras selectas] Moscow.

ФРОММ Э. [Fromm, Е.] (1986): Иметь или быть? [¿Tener o ser?] Moscow.

"Модель делового совершенства: глоссарий и методы" [“El modelo de la perfección laboral: glosario y métodos"] en Методы менеджмента качества [Los métodos de la calidad de gestión], 9, pp. 45-49.

\section{Anexos}

Tabla 1. Las características generales de los encuestados

\begin{tabular}{|c|c|}
\hline Característica & $\begin{array}{c}\% \text { del total } \\
\text { encuestados }\end{array}$ \\
\hline \multicolumn{2}{|l|}{ País } \\
\hline Rusia & 27.6 \\
\hline EEUU & 16.4 \\
\hline Gran Bretaña & 14.4 \\
\hline España & 12.3 \\
\hline Italia & 10.1 \\
\hline Alemania & 11.6 \\
\hline Francia & 7.6 \\
\hline \multicolumn{2}{|l|}{ Género } \\
\hline masculino & 46,2 \\
\hline femenino & 53,7 \\
\hline \multicolumn{2}{|l|}{ Edad } \\
\hline hasta 21 años & 37,5 \\
\hline $22-34$ años & 27,8 \\
\hline $35-55$ años & 20,8 \\
\hline mayores de 55 años & 13,9 \\
\hline \multicolumn{2}{|l|}{ Formación profesional } \\
\hline Bachillerato & 3,8 \\
\hline FP & 28,2 \\
\hline Estudios universitarios & 21,1 \\
\hline Estudios universitarios no acabados (estudiante) & 28,2 \\
\hline Postgrado & 8,5 \\
\hline \multicolumn{2}{|l|}{ Tipo de actividad profesional } \\
\hline Industria (transporte, comunicaciones, construcción) & 7,2 \\
\hline Agricultura & 3,6 \\
\hline Comercio, hostelería, servicios sociales de la comunidad, otros servicios sociales & 5,5 \\
\hline Sector sanitario, seguridad social & 4,5 \\
\hline Educación & 10,9 \\
\hline Cultura & 5,8 \\
\hline Bancas, instituciones financieras & 5,4 \\
\hline Organos directivos y ejecutivos & 3,8 \\
\hline Organizaciones sociales & 4,3 \\
\hline Medios de comunicación & 8,5 \\
\hline Jubilados & 4,3 \\
\hline
\end{tabular}




\begin{tabular}{|l|c|}
\hline Estudiantes de institutos y universitarios & 19,8 \\
\hline Servicio militar, órganos de orden público & 4,2 \\
\hline Parados, amas de casa, personas de permiso de cuidados, etc. & 5,1 \\
\hline Otros ámbitos & 7,1 \\
\hline Puesto de trabajo & 9,7 \\
\hline Altos directivos (directores, sus sustitutos, director técnico, especialista, oficial.......) & 25,9 \\
\hline $\begin{array}{l}\text { Mandos directivos intermedios (maestro, jefe de departamento, jefe del área, jefe de } \\
\text { equipo, etc.) }\end{array}$ & 64,4 \\
\hline Empleado (operario, administrativo) & \multicolumn{2}{|c|}{} \\
\hline
\end{tabular}

Tabla 2. El grado de importancia de valores diferentes para las distintas culturas de negocios (puntuación media, calculada según toda la evaluación puesta en los cuestionarios rellenados por todos los participantes del estudio)

\begin{tabular}{|c|c|c|c|c|c|c|c|}
\hline \multirow[b]{2}{*}{ Valores } & \multicolumn{7}{|c|}{ Tipo de la cultura de negocios } \\
\hline & rusa & $\begin{array}{l}\text { estado- } \\
\text { unidense }\end{array}$ & inglesa & española & italiana & alemana & francesa \\
\hline Seguridad & 2,98 & 3,61 & 3,64 & 3,22 & 2,76 & 3,88 & 3,41 \\
\hline Religiosidad & 2,65 & 3,00 & 2,71 & 2,94 & 3,16 & 2,34 & 2,55 \\
\hline Poder & 3,43 & 4,11 & 3,56 & 3,08 & 3,00 & 3,80 & 3,26 \\
\hline Deber & 3,07 & 3,37 & 3,37 & 2,76 & 2,54 & 3,69 & 3,04 \\
\hline Abundancia & 3,15 & 3,86 & 3,26 & 3,20 & 3,09 & 3,65 & 3,12 \\
\hline Salud & 2,94 & 2,89 & 3,22 & 3,50 & 3,18 & 3,36 & 3,17 \\
\hline Amor & 2,75 & 2,87 & 2,76 & 3,49 & 3,46 & 2,71 & 3,24 \\
\hline Independencia & 3,04 & 3,74 & 3,55 & 2,92 & 2,87 & 3,45 & 3,16 \\
\hline Formación & 3,17 & 3,63 & 3,59 & 3,06 & 2,92 & 3,96 & 3,41 \\
\hline Igualdad & 2,54 & 2,94 & 3,11 & 3,05 & 2,76 & 3,12 & 3,23 \\
\hline Libertad & 2,54 & 3,26 & 3,27 & 3,34 & 3,04 & 3,13 & 3,19 \\
\hline Familia & 3,03 & 3,02 & 2,91 & 3,59 & 3,57 & 2,97 & 3,10 \\
\hline Justicia & 2,60 & 3,01 & 3,20 & 2,78 & 2,80 & 3,26 & 3,07 \\
\hline Amor por la patria & 3,37 & 4,00 & 3,49 & 2,99 & 3,28 & 3,41 & 3,46 \\
\hline Tolerancia & 2,47 & 2,86 & 3,07 & 2,96 & 2,86 & 2,96 & 2,83 \\
\hline Creatividad & 2,77 & 3,31 & 3,15 & 3,07 & 2,94 & 3,26 & 3,18 \\
\hline Trabajo & 3,15 & 3,44 & 3,37 & 2,83 & 2,81 & 3,87 & 3,22 \\
\hline Placer & 2,55 & 3,07 & 2,77 & 3,61 & 3,46 & 2,79 & 3,19 \\
\hline Éxito & 3,08 & 3,81 & 3,60 & 3,18 & 3,06 & 3,69 & 3,34 \\
\hline Democracia & 2,33 & 3,16 & 3,13 & 3,14 & 2,85 & 3,37 & 3,13 \\
\hline Progreso & 2,78 & 3,60 & 3,43 & 3,01 & 2,97 & 3,70 & 3,10 \\
\hline Riqueza & 3,11 & 3,74 & 3,36 & 3,13 & 3,11 & 3,71 & 3,39 \\
\hline Conformismo & 2,82 & 2,79 & 2,77 & 3,25 & 3,01 & 2,64 & 2,72 \\
\hline Eficiencia & 3,02 & 3,62 & 3,42 & 3,01 & 2,85 & 3,84 & 3,22 \\
\hline Prosperidad & 3,08 & 3,60 & 3,28 & 3,24 & 3,05 & 3,60 & 3,30 \\
\hline Utilidad & 2,91 & 3,41 & 3,22 & 3,04 & 2,84 & 3,62 & 3,10 \\
\hline Ciencia & 3,05 & 3,61 & 3,18 & 3,00 & 2,59 & 3,55 & 3,11 \\
\hline Poder judicial & 2,57 & 3,26 & 3,31 & 2,88 & 2,72 & 3,35 & 3,00 \\
\hline Confort & 2,72 & 3,32 & 3,28 & 3,40 & 3,14 & 3,22 & 3,22 \\
\hline Libertad personal & 2,63 & 3,27 & 3,29 & 3,20 & 2,95 & 3,11 & 3,20 \\
\hline Sinceridad & 2,77 & 2,69 & 3,06 & 2,98 & 2,74 & 3,08 & 2,85 \\
\hline
\end{tabular}


Tabla 3. Jerarquía de valores diferentes para las distintas culturas de negocios (media según todos los encuestados)

\begin{tabular}{|c|c|c|c|c|c|c|c|}
\hline \multirow{2}{*}{ Valor } & \multicolumn{7}{|c|}{ Tipo de cultura de negocios } \\
\hline & rusa & estado-unidense & inglesa & española & italiana & alemana & francesa \\
\hline 1 & Poder & Poder & Seguridad & Placer & Familia & Formación & $\begin{array}{l}\text { Amor por la } \\
\text { patria }\end{array}$ \\
\hline 2 & $\begin{array}{l}\text { Amor por la } \\
\text { patria }\end{array}$ & $\begin{array}{l}\text { Amor por la } \\
\text { patria }\end{array}$ & Éxito & Familia & Placer & Seguridad & Formación \\
\hline 3 & Formación & Abundancia & Formación & Salud & Amor & Trabajo & Seguridad \\
\hline 4 & Trabajo & Éxito & Poder & Amor & $\begin{array}{l}\text { Amor por la } \\
\text { patria }\end{array}$ & Eficiencia & Riqueza \\
\hline 5 & Abundancia & Riqueza & Independencia & Confort & Salud & Poder & Éxito \\
\hline 6 & Riqueza & Independencia & $\begin{array}{l}\text { Amor por la } \\
\text { patria }\end{array}$ & Libertad & Religiosidad & Riqueza & Prosperidad \\
\hline 7 & Éxito & Formación & Progreso & Conformismo & Confort & Progreso & Poder \\
\hline 8 & Prosperidad & Eficiencia & Eficiencia & Prosperidad & Riqueza & Éxito & Amor \\
\hline 9 & Deber & Ciencia & Trabajo & Seguridad & Abundancia & Deber & Igualdad \\
\hline 10 & Ciencia & Seguridad & Deber & Abundancia & Éxito & Éxito & Trabajo \\
\hline 11 & Independencia & Prosperidad & Riqueza & $\begin{array}{l}\text { Libertad } \\
\text { personal }\end{array}$ & Prosperidad & Utilidad & Eficiencia \\
\hline 12 & Familia & Progreso & Poder judicial & Éxito & Libertad & Prosperidad & Confort \\
\hline 13 & Eficacia & Trabajo & $\begin{array}{l}\text { Libertad } \\
\text { personal }\end{array}$ & Democracia & Conformismo & Ciencia & $\begin{array}{l}\text { Libertad } \\
\text { personal }\end{array}$ \\
\hline 14 & Seguridad & utilidad & prosperidad & riqueza & poder & independencia & libertad \\
\hline 15 & salud & deber & confort & poder & progreso & $\begin{array}{l}\text { Amor por la } \\
\text { patria }\end{array}$ & placer \\
\hline 16 & utilidad & confort & libertad & creatividad & $\begin{array}{l}\text { Libertad } \\
\text { personal }\end{array}$ & democracia & creatividad \\
\hline 17 & conformismo & creatividad & abundancia & formación & creatividad & salud & salud \\
\hline 18 & progreso & $\begin{array}{l}\text { Libertad } \\
\text { personal }\end{array}$ & utilidad & igualdad & formación & Poder judicial & independencia \\
\hline 19 & creatividad & Poder judicial & salud & utilidad & independencia & creatividad & democracia \\
\hline 20 & sinceridad & libertad & justicia & eficiencia & tolerancia & justicia & abundancia \\
\hline 21 & amor & democracia & ciencia & progreso & democracia & confort & ciencia \\
\hline 22 & confort & placer & creatividad & ciencia & eficiencia & libertad & progreso \\
\hline 23 & religiosidad & familia & democracia & $\begin{array}{l}\text { Amor por la } \\
\text { patria }\end{array}$ & utilidad & igualdad & utilidad \\
\hline 24 & $\begin{array}{l}\text { Libertad } \\
\text { personal }\end{array}$ & justicia & igualdad & sinceridad & trabajo & $\begin{array}{l}\text { Libertad } \\
\text { personal }\end{array}$ & familia \\
\hline 25 & justicia & religiosidad & tolerancia & tolerancia & justicia & sinceridad & justicia \\
\hline 26 & Poder judicial & igualdad & sinceridad & religiosidad & seguridad & familia & deber \\
\hline 27 & placer & salud & familia & independencia & igualdad & tolerancia & Poder judicial \\
\hline 28 & libertad & amor & placer & Poder judicial & sinceridad & placer & sinceridad \\
\hline 29 & igualdad & tolerancia & conformismo & trabajo & Poder judicial & amor & tolerancia \\
\hline 30 & tolerancia & conformismo & amor & justicia & ciencia & conformismo & conformismo \\
\hline 31 & democracia & sinceridad & religiosidad & deber & deber & religiosidad & religiosidad \\
\hline
\end{tabular}


Tabla 4. Grado de importancia de diferentes valores para las distintas cultura de negocios (valor ponderado), según la opinión de los españoles (valor ponderado) (valor ponderado, calculado considerando todas las evaluaciones indicadas en los cuestionarios rellenos por sujetos españoles)

\begin{tabular}{|c|c|c|c|c|c|c|c|}
\hline \multirow[b]{2}{*}{ Valores } & \multicolumn{7}{|c|}{ Tipo de cultura de negocios } \\
\hline & rusa & $\begin{array}{l}\text { estado- } \\
\text { unidense }\end{array}$ & inglesa & española & italiana & alemana & francesa \\
\hline Seguridad & 2,94 & 3,57 & 3,57 & 3,22 & 2,69 & 3,82 & 3,36 \\
\hline Religiosidad & 2,67 & 2,98 & 2,73 & 2,91 & 3,10 & 2,31 & 2,56 \\
\hline Poder & 3,36 & 4,14 & 3,59 & 3,10 & 2,97 & 3,83 & 3,31 \\
\hline Deber & 3,06 & 3,37 & 3,34 & 2,74 & 2,49 & 3,68 & 3,07 \\
\hline Abundancia & 3,05 & 3,77 & 3,21 & 3,19 & 3,02 & 3,59 & 3,05 \\
\hline Salud & 2,89 & 2,81 & 3,15 & 3,48 & 3,13 & 3,31 & 3,14 \\
\hline Amor & 2,65 & 2,86 & 2,78 & 3,45 & 3,45 & 2,77 & 3,20 \\
\hline Independencia & 3,01 & 3,68 & 3,53 & 2,91 & 2,81 & 3,45 & 3,14 \\
\hline Formación & 3,11 & 3,64 & 3,56 & 3,06 & 2,88 & 3,96 & 3,39 \\
\hline Igualdad & 2,52 & 2,86 & 3,11 & 3,06 & 2,75 & 3,09 & 3,18 \\
\hline Libertad & 2,41 & 3,18 & 3,24 & 3,31 & 2,97 & 3,12 & 3,15 \\
\hline Familia & 2,95 & 2,99 & 2,86 & 3,56 & 3,46 & 2,94 & 3,08 \\
\hline Justicia & 2,55 & 2,95 & 3,13 & 2,74 & 2,72 & 3,22 & 3,04 \\
\hline Amor por la patria & 3,39 & 3,97 & 3,48 & 2,95 & 3,24 & 3,36 & 3,39 \\
\hline Tolerancia & 2,47 & 2,79 & 2,99 & 2,94 & 2,83 & 2,90 & 2,82 \\
\hline Creatividad & 2,75 & 3,31 & 3,14 & 3,04 & 2,85 & 3,29 & 3,17 \\
\hline Trabajo & 3,17 & 3,48 & 3,39 & 2,82 & 2,80 & 3,86 & 3,26 \\
\hline Placer & 2,50 & 3,03 & 2,78 & 3,60 & 3,44 & 2,80 & 3,13 \\
\hline Éxito & 3,02 & 3,80 & 3,56 & 3,19 & 3,04 & 3,69 & 3,33 \\
\hline Democracia & 2,35 & 3,09 & 3,06 & 3,14 & 2,79 & 3,34 & 3,10 \\
\hline Progreso & 2,83 & 3,58 & 3,43 & 2,99 & 2,93 & 3,70 & 3,10 \\
\hline Riqueza & 3,09 & 3,70 & 3,38 & 3,13 & 3,07 & 3,73 & 3,36 \\
\hline \begin{tabular}{|l|} 
Conformismo \\
\end{tabular} & 2,84 & 2,78 & 2,74 & 3,26 & 3,07 & 2,62 & 2,68 \\
\hline Eficiencia & 3,03 & 3,59 & 3,42 & 3,01 & 2,78 & 3,81 & 3,20 \\
\hline Prosperidad & 3,08 & 3,58 & 3,23 & 3,22 & 3,04 & 3,57 & 3,27 \\
\hline Utilidad & 2,96 & 3,38 & 3,22 & 3,09 & 2,77 & 3,58 & 3,10 \\
\hline Ciencia & 3,11 & 3,64 & 3,17 & 3,01 & 2,53 & 3,54 & 3,11 \\
\hline Poder judicial & 2,62 & 3,25 & 3,28 & 2,89 & 2,67 & 3,29 & 3,00 \\
\hline Confort & 2,71 & 3,29 & 3,26 & 3,39 & 3,09 & 3,18 & 3,17 \\
\hline Libertad personal & 2,64 & 3,24 & 3,23 & 3,21 & 2,87 & 3,10 & 3,18 \\
\hline Sinceridad & 2,84 & 2,70 & 3,06 & 2,98 & 2,70 & 3,04 & 2,86 \\
\hline
\end{tabular}


Tabla 5. Jerarquía de diferentes valores para las distintas culturas de negocios, según la opinión de los españoles encuestados

\begin{tabular}{|c|c|c|c|c|c|c|c|}
\hline \multirow[b]{2}{*}{ Valores } & \multicolumn{7}{|c|}{ Tipo de cultura de negocios } \\
\hline & rusa & $\begin{array}{l}\text { estado- } \\
\text { unidense }\end{array}$ & inglesa & española & italiana & alemana & francesa \\
\hline 1 & $\begin{array}{l}\text { Amor por la } \\
\text { patria }\end{array}$ & poder & poder & placer & familia & formación & formación \\
\hline 2 & poder & $\begin{array}{l}\text { Amor por la } \\
\text { patria }\end{array}$ & seguridad & familia & amor & trabajo & $\begin{array}{l}\text { Amor por la } \\
\text { patria }\end{array}$ \\
\hline 3 & trabajo & Éxito & éxito & salud & placer & poder & seguridad \\
\hline 4 & formación & abundancia & formación & amor & $\begin{array}{l}\text { Amor por la } \\
\text { patria }\end{array}$ & seguridad & riqueza \\
\hline 5 & ciencia & riqueza & independencia & confort & salud & eficiencia & éxito \\
\hline 6 & riqueza & independencia & $\begin{array}{l}\text { Amor por la } \\
\text { patria }\end{array}$ & libertad & religiosidad & riqueza & poder \\
\hline 7 & prosperidad & formación & progreso & conformismo & confort & progreso & prosperidad \\
\hline 8 & deber & ciencia & eficiencia & inseguridad & conformismo & éxito & trabajo \\
\hline 9 & abundancia & eficiencia & trabajo & prosperidad & riqueza & deber & eficiencia \\
\hline 10 & eficiencia & prosperidad & riqueza & $\begin{array}{l}\text { Libertad } \\
\text { personal }\end{array}$ & prosperidad & abundancia & amor \\
\hline 11 & éxito & progreso & deber & éxito & éxito & utilidad & $\begin{array}{l}\text { Libertad } \\
\text { personal }\end{array}$ \\
\hline 12 & independencia & seguridad & Poder judicial & abundancia & abundancia & prosperidad & igualdad \\
\hline 13 & utilidad & trabajo & confort & democracia & libertad & ciencia & creatividad \\
\hline 14 & familia & utilidad & libertad & riqueza & poder & independencia & confort \\
\hline 15 & seguridad & deber & prosperidad & poder & progreso & $\begin{array}{l}\text { Amor por la } \\
\text { patria }\end{array}$ & libertad \\
\hline 16 & salud & creatividad & $\begin{array}{l}\text { Libertad } \\
\text { personal }\end{array}$ & utilidad & formación & democracia & independencia \\
\hline 17 & conformismo & confort & utilidad & formación & $\begin{array}{l}\text { Libertad } \\
\text { personal }\end{array}$ & salud & salud \\
\hline 18 & sinceridad & Poder judicial & abundancia & igualdad & creatividad & creatividad & placer \\
\hline 19 & progreso & $\begin{array}{l}\text { Libertad } \\
\text { personal }\end{array}$ & ciencia & creatividad & tolerancia & Poder judicial & ciencia \\
\hline 20 & creatividad & libertad & salud & eficiencia & independencia & justicia & progreso \\
\hline 21 & confort & democracia & creatividad & ciencia & trabajo & confort & utilidad \\
\hline 22 & religiosidad & placer & justicia & progreso & democracia & libertad & democracia \\
\hline 23 & amor & familia & igualdad & sinceridad & eficiencia & $\begin{array}{l}\text { Libertad } \\
\text { personal }\end{array}$ & familia \\
\hline 24 & $\begin{array}{l}\text { Libertad } \\
\text { personal }\end{array}$ & religiosidad & democracia & $\begin{array}{l}\text { Amor por la } \\
\text { patria }\end{array}$ & utilidad & igualdad & deber \\
\hline 25 & Poder judicial & justicia & sinceridad & tolerancia & igualdad & sinceridad & abundancia \\
\hline 26 & justicia & amor & tolerancia & independencia & justicia & familia & justicia \\
\hline 27 & igualdad & igualdad & familia & religiosidad & sinceridad & tolerancia & Poder judicial \\
\hline 28 & placer & salud & placer & Poder judicial & seguridad & placer & sinceridad \\
\hline 29 & tolerancia & tolerancia & amor & trabajo & Poer judicial & amor & tolerancia \\
\hline 30 & liberta & conformismo & conformismo & deber & ciencia & conformismo & conformismo \\
\hline 31 & democracia & sinceridad & religiosidad & justicia & deber & religiosidad & religiosiadad \\
\hline
\end{tabular}

